\title{
Experiencing a word can prime its accessibility and its associative connections to related words
}

\author{
DOUGLAS L. NELSON and LEILANI B. GOODMON \\ University of South Florida, Tampa, Florida
}

\begin{abstract}
This paper reports the results of manipulations of word features for the magnitude of priming effects. In Experiment 1, the printed frequency of the target words and the number of connections among their associates were varied, and during testing participants were given cues and asked to produce the first word to come to mind as rapidly as possible in implicit free association. Priming effects were greater for lowfrequency words and for those with many connections among their associates. In Experiments 2 and 3, target words were presented under incidental or intentional learning conditions during study, and the presence of direct preexisting connections from target to cue and from cue to target was varied. Priming effects were greater when either connection was present, with each connection having additive effects. In Experiments 4 and 5, priming effects for indirect links (shared associates and mediators) were examined. The results of these experiments indicate that priming in free association depends on both the general accessibility of the target as a response and the strengthening of direct target-to-cue connections. These findings raise problems for theories that attribute priming only to target accessibility or only to target-to-cue association.
\end{abstract}

Ebbinghaus (1885/1964) anticipated contemporary research on memory in suggesting that information is sometimes brought to mind as a result of intentional acts and sometimes as a result of automatic, unconscious processes. In recent research, these two forms of remembering are implemented by manipulating test instructions. Explicit test instructions ask participants to recall, recognize, or judge information as it relates to the study episode. In contrast, implicit test instructions make no reference to this episode and generally disguise the fact that the procedure is a test of memory. Explicit tests are designed to engage intentional acts of remembering, whereas implicit tests are designed to prompt automatic occurrences of memory. In either test, interest is focused on the success of recovering the target experience produced during the study episode. Success under explicit instructions is usually described by the name given the task, such as cued recall or recognition. Success under implicit instructions is attributed to priming, defined as an increase in target recovery in a study condition relative to an unstudied control.

This article focuses on a single issue linked to a single implicit test procedure: free association. In this procedure,

This research was supported by Grant MH16360 from the National Institute of Mental Health to D.L.N. The authors thank Nan Zhang, Marie Rasmussen, and Erin Cotrone for their help in collecting the data and Cathy McEvoy for her comments on an earlier draft. Correspondence concerning this article should be addressed to D. L. Nelson, Department of Psychology, University of South Florida, Tampa, FL 33620-8200(e-mail: dnelson2@chuma1.cas.usf.edu).

-Accepted by previous editorial team a list of words is studied under incidental or intentional learning conditions, and then, during testing, related words are shown as cues or primes, with participants asked to produce the first word that comes to mind as rapidly as possible. The preexisting connections between the words presented as free-association cues and the studied words are never mentioned, and normally, about one half of these cues are related to studied words, and the rest are not. For example, suppose that the word BROOM appeared as a prime cue. Interest is focused on the probability that CLOSET will be produced as a response by those who saw it during study and those who did not, and priming is said to have occurred to the extent that studying CLOSET increases its relative occurrence in free association despite the absence of direct incentives to recall it.

The main issue in the present paper is not whether priming effects occur because they have been observed under a wide variety of conditions in the free-association procedure (e.g., Cramer, 1968; Fox, 1968; Nelson, Schreiber, \& Holley, 1992; Storms, 1958; Vaidya et al., 1997; Weldon \& Coyote, 1996; Zeelenberg, Shiffrin, \& Raaijmakers, 1999). The issue is what causes such priming effects. One possibility is that studying the target heightens its activation as a preexisting representation. Heightened activation, in turn, increases target accessibility, which increases the probability that the target will be produced as a response to any cue that normally produces it in free association. The target accessibility hypothesis assumes that priming produces increased accessibility to all related cues (Anderson, 1983; Chappell \& Humphreys, 1994; Fox, 1968; Horowitz, Brown, \& Weissbluth, 1964; Horowitz \& Prytulak, 1969; Humphreys, Tehan, O'Shea, \& Bolland, 2000; Mandler, 
1980). For example, as is illustrated in panel A of Figure 1, studying CLOSET does not activate broom, because there is no measurable backward closet-to-broom connection according to free-association norms. ${ }^{1}$ In the figure, there is no arrow going from CLOSET to BROOM. However, studying CLOSET should increase the probability that it will be produced as a response to BROOM, because there is a measurable forward broom-to-closet association, as is indicated by the presence of an arrow. In contrast, associates of CLOSET that do not have preexisting forward links to it, such as DOOR, will not produce priming effects. According to the accessibility hypothesis, priming will be affected by the presence of forward links, but not by the presence of backward links. In general, variables that affect target accessibility should also affect the magnitude of observed priming effects. For example, level-of-processing manipulations have shown that semantic processing focused on the target during study increases the magnitude of priming effects relative to processing that focuses on the nonsemantic features of the target (Vaidya et al., 1997; Weldon \& Coyote, 1996).

A second explanation of priming effects holds that priming occurs only when the target activates preexisting backward connections to words that subsequently serve as the prime cue (Humphreys, Bain, \& Pike, 1989; Storms, 1958; Zeelenberg et al., 1999). The target association hypothesis attributes priming to the temporary strengthening of connections to the target's associates. For example, as is shown in panel B of Figure 1, studying CLOSET primes the closet-to-door link and increases the probability that the cue DOOR will produce "closet" as a response even though it has no apparent forward link to CLOSET . In contrast, such study would not affect the probability that "closet" will be produced to a cue that is not activated by the target, such as BROOM, because it is not a reliable associate of CLOSET . The target association hypothesis relies on the encoding specificity principle for explaining priming effects (Humphreys \& Galbraith, 1975; Nelson, McKinney, Gee,
\& Janczura., 1998; Tulving \& Thomson, 1973). It predicts that priming will be obtained only when the prime cue has been encoded during the study trial, regardless of whether a measurable forward link is present. Furthermore, the association hypothesis also predicts that indirect connections, such as shared associates, will increase priming. When the target and the test prime are each linked to the same associate, that associate is shared-for example, both CLOSET and HANGER are linked to coat. Shared associates increase the probability of cued recall, and they presumably will increase priming because they provide another means for linking the cue to the target (Nelson, Bennett, \& Leibert, 1997).

The issue of whether priming is caused by boosting the accessibility of the target as an independent representation or by strengthening its preexisting connections to other words is theoretically important because models make different assumptions. For example, several models assume that priming can result from accessibility. Mandler (1980) assumed that experiencing a word enhances the organization of its perceptual features, making it seem more familiar independent of its relations to other words in memory. Similarly, Chappell and Humphreys's (1994) auto-associative model also produces priming in free association by strengthening intraitem features. Jacoby and Hollingshead (1990) proposed a generation-recognition model that is based on the assumption that studying a word increases processing fluency. The model predicts that increased fluency will facilitate target generation on both explicit and implicit tests. In Anderson's (1983) ACT*, node strength determines whether two words are associated. The strength of an A-B association is determined solely by the strength of $B$ relative to the sum of the strengths of all items linked to A. This ratio rule determines node strength, and $\mathrm{ACT}^{*}$ assumes that priming is caused by target accessibility. In each of these approaches, variables that affect target accessibility should affect the magnitude of observed priming effects. In contrast to ac-

\section{A. Target accessibility hypothesis}

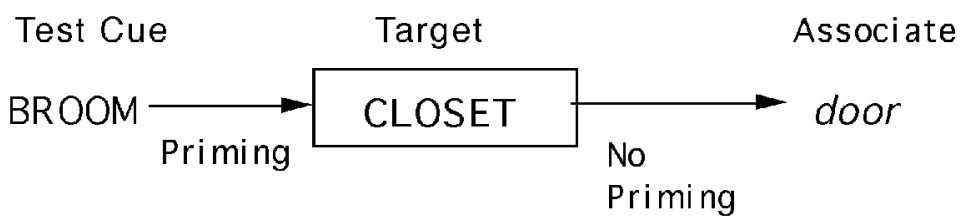

B. Target association hypothesis

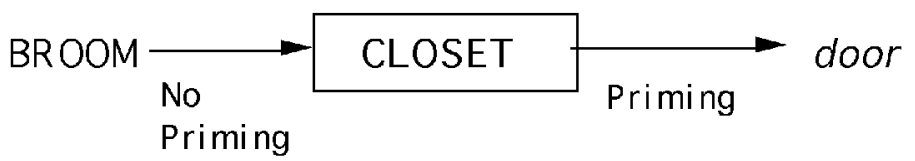

Figure 1. Illustrations of priming predictions based on the target accessibility hy pothesis (panel A) and the target association hypothesis (panel B). The testcue-to-target connection shown by the arrow from BROOM to CLOSET is a forward connection, and the target-to-associate connection shown by the arrow from CLOSET to DOOR is a backward connection. 
cessibility explanations, the Matrix model captures priming in associations between words (Humphreys et al., 1989; also see Zeelenberg et al., 1999). Presenting a word activates its representation, as well as the representations of its related associates, but importantly, priming occurs only when the connections among the studied word and its potential cues are stored. The activation of related associates provides an opportunity for covert learning, and if such learning occurs, priming will be observed.

PIER 2 contrasts with all of these models in assuming that studying a target primes its implicit representation, as well as preexisting links to related associates and the links among them (Nelson et al., 1998; Nelson \& Zhang, 2000). PIER 2 was developed to explain the effects of implicitly activated associates on cued recall, and this paper represents an attempt to extend the model to priming effects. The model will be described in more detail later, but in broad terms, it assumes that studying a word in a list produces a dual representation in memory. An explicit representation is created that is the result of applying conscious processing operations, such as rehearsal, imagery, rating words for pleasantness, naming vowels, and so on. In addition, an implicit representation is activated in long-term working memory (LTWM) that is the result of an automatic comprehension process. This representation encompasses the target, connections to its immediate associates, and the connections that bind the target and its associates together as a coherent unit. The model further assumes that explicit and implicit representations contribute independently to target recovery under explicit testing conditions. Under implicit testing conditions, however, only the implicit representation affects memory performance. Because the implicit representation contributes to both explicit and implicit tests, the model predicts that both tests will be affected by manipulations that strengthen a target's implicit representation, such as its frequency of occurrence and its connectivity among its associates. When a target is studied, low-frequency and dense connections among its associates increase its activation level and make it more accessible to related cues. In addition, consistent with the association hypothesis, priming also is increased by preexisting connections between words serving as targets and those serving as test cues. Finally, because indirect connections involving shared associates and mediators are also computed in the model, it predicts that such connections will increase priming.

The theoretical implications underlying the causes of priming are important, but the findings on this issue are sparse. Studies reporting priming effects have focused on manipulating levels of processing (e.g., Nelson et al., 1992; Vaidya et al., 1997), pictures versus words as materials (e.g., Weldon \& Coyote, 1996), and forward cue-totarget strength (e.g., Fox, 1968). However, one problem in these studies is that the strengths of the target-to-cue connections are unknown, and these links are important for distinguishing between theories. There are, however, two relevant papers. Storms (1958) selected pairs of words having weak forward cue-to-target connections (e.g., bird to eagle) but strong backward target-to-cue connections (e.g., eagle to bird). He found that brief study of the target increased the probability that the test cue generated it in free association, as compared with its nonstudied normative probability. Studying eagle increased its probability of occurrence as a response to bird, which normally produced it in free association at very low levels. Ancillary analyses led Storms to attribute this effect to the strengthening of the backward target-to-cue connection, rather than to target accessibility, or what he called "indiscriminate sensitization" (p. 394). This effect was reportedly replicated by Segal and Cofer (1960), who introduced the term priming into this context, and by Martin (1964), who reported that the magnitude of the priming effect rapidly declined to baseline levels.

More recently, Zeelenberg et al. (1999) directly evaluated the target accessibility and target association hypotheses. Participants provided pleasantness ratings on a series of targets, and one of two types of prime cues were used to prompt target recovery in an implicit free-association task. One type consisted of unidirectional cues that had strong forward but no apparent backward connections with their targets. The second type were bidirectionally related, having both strong forward and strong backward connections. They reasoned that the target accessibility hypothesis predicts priming in both conditions, because experiencing the target during study should make it more probable as a response in free association to any cue that normally produces it as a response. In contrast, they argued that the target association hypothesis predicts that priming will occur only for bidirectional cues, because only these cues have viable preexisting backward target-to-cue connections. The results indicated that priming effects were found in the bidirectional condition, but not in the unidirectional condition, and thus they failed to support the target accessibility hypothesis. The results of Zeelenberg et al. support the Matrix model, but they are inconsistent with ACT* and the autoassociative model, and they are only partially consistent with PIER 2.

The present experiments were designed to reevaluate the accessibility and association hypotheses. Earlier research on intentional extralist cuing has shown that recall varies with target frequency and the number of preexisting connections among a target's associates, or what is called connectivity. Recall is higher for lower frequency targets (Nelson \& McEvoy, 2000; Nelson \& Xu, 1995) and for targets with higher levels of connectivity (e.g., Nelson et al., 1998). In PIER 2, such effects are attributed to priming. Low frequency and high connectivity increase the activation level of the target as an implicit representation in LTWM (Nelson et al., 1998; Nelson \& Zhang, 2000). In Experiment 1, the target accessibility hypothesis was evaluated in an implicit test, as well as in an explicit test. Targets studied under intentional learning conditions systematically varied in word frequency and connectivity. One group had freeassociation instructions that asked them to produce the first word to come to mind to each test cue, and one group was 
given cued-recall instructions. For each group, half of the test cues were related to the targets, and half were not, with both types of cues randomly intermixed. If PIER 2's prediction is correct, priming will be greater for words lower in frequency and higher in connectivity, and these effects will be found in both explicit and implicit tests.

In Experiments 2 and 3, the target association hypothesis was reassessed with three changes, as compared with the procedures used in the Zeelenberg et al. (1999) study. First, instead of comparing only bidirectional and unidirectional pairs, the presence of forward cue-to-target associations was crossed with the presence of backward target-to-cue connections in a factorial design. This procedure allows direct evaluation of the role of each connection. Second, target accessibility was held constant by using the same target words in all conditions. Differences in priming attributable to associative links cannot be attributed to differences in perceptual or intraitem features. Third, the number of study trials, one or two, was varied prior to testing. A second study trial should strengthen the explicit representation of the target but have little or no effect on its implicit representation. In PIER 2, activation is maintained until conceptually based attention has been switched to another task. Hence, number of study trials served as a manipulation check to determine whether the implicit test was contaminated by intentional recall (see Humphreys et al., 2000, for a full discussion of this variable).

Type of processing was varied between experiments. The participants rated the pleasantness of the targets in Experiment 2, as in Zeelenberg et al. (1999), and they encoded the items under intentional learning conditions in Experiment 3. PIER 2 predicted that the priming effects related to the presence of forward and backward connections should be apparent for each encoding condition. Weaker effects, however, were expected for intentional learning instructions. Pleasantness ratings under incidental encoding conditions focus conceptual processing directly on each target as an individual unit in memory, whereas intentional instructions tend to encourage rehearsing subgroupings of list items together. Under intentional instructions, conceptual attention is focused on developing episodic links among the list items, and to the extent that this focus diverts attention away from the study word as an independent unit in memory, PIER 2 predicts a reduction in priming. Both attention shifts from semantic to nonsemantic features during study (e.g., Nelson, Bennett, Gee, Schreiber, \& McKinney, 1993) and attention shifts to conceptually different tasks immediately after study (Nelson et al., 1998) reduce the influence of connections among the associates in explicit cued recall, and similar effects were expected on implicit tests. In PIER 2, attention switching reduces access to the implicit representation. Finally, Experiments 4 and 5 echoed Experiments 2 and 3, but the presence-absence of indirect, as opposed to direct, connections was varied. Experiment 4 varied the presenceabsence of shared associate and mediated connections following pleasantness ratings, and Experiment 5 varied them following intentional learning instructions.

\section{EXPERIMENT 1}

The purpose of Experiment 1 was to explore the target accessibility hypothesis by investigating how two of the target's item-specific features affect priming in the implicit free-association test. The participants studied words that were either low or high in frequency and that varied in number of connections among their associates. The question is whether these variables will have the same effects on priming as they have in cued recall when forward and backward strength, as well as other features, are controlled. Such effects would indicate that priming intrinsic to a word's features can differentially influence its accessibility to a related cue.

Connectivity among the associates of a word should affect priming because it theoretically increases the activation level of the target (Nelson et al., 1998). An evaluation of equations for determining how connectivity increases target activation showed that a rule that summed the pairwise connection strengths among the target's associates effectively predicted both extralist cued recall (Nelson \& Zhang, 2000) and recognition (Nelson, Zhang, \& McKinney, 2001). The rule assumes that the target's activation level increases as an additive function of how strongly it is linked to each of its associates and how strongly its associates are linked to each other and to the target. An illustrative computation of the effects of connectivity for the studied word RUM is shown in Table 1 (resonant links to the target from its associates are ignored here). The values in the cells of this table were taken from free-association norms that were used to index preexisting connection strengths for each pair of words in the set (Nelson, McEvoy, \& Schreiber, 1999). For example, the cue RUM produces the associate coke with a probability of .28, and the cue DRINK, which is one of RUM's associates produces coke at .06. To determine how much strength coke adds to the activation of RUM , these values are added together $(.28+$ $.06=.34)$. This value is then cumulated across each associate in the set to index net target activation on the basis of prior pairwise connections among the items in the set. PIER 2 assumes that, over time and context, pairwise connections making up any word's associative network are strengthened independently in language use and that these connections self-organize into coherent sets. Experiencing a word activates its associates and the pairwise connections that bind them together as a set. The binding mechanism underlying this rule is conceptualized in terms of parallel rather than spreading activation, and as can be seen in Table 1, the more pairwise connections there are among the associates and the stronger these connections are, the higher the level of predicted target activation.

PIER 2 feeds the values for the target and its associates into linked equations in order to predict cued-recall and priming performance, but discussion of these equations will be postponed to the General Discussion section. What is important for now is that the implicit representation underlying both cued recall and priming is a result of computing the intersection of the test cue and its associates with 
Table 1

Activation Strength of the Target RuM Attributed

to Preexisting Connectivity Among its Associates

\begin{tabular}{lccccccccc}
\hline & Coke & Drink & Liquor & Vodka & Alcohol & Whiskey & Beer & Drunk & Booze \\
\hline Rum & .28 & .16 & .16 & .10 & .10 & .04 & .03 & .03 & .02 \\
Coke & & .22 & & & & & & & \\
Drink & .06 & & .03 & .02 & .05 & .10 & .06 & & .12 \\
Liquor & & .07 & & .05 & .11 & & .13 & .12 & .05 \\
Vodka & & .19 & .07 & & .12 & .01 & .01 & .12 & \\
Alcohol & & .15 & & .01 & & & .24 & .11 & \\
Whiskey & & .08 & .08 & & .05 & & .05 & .12 & .14 \\
Beer & & .18 & & .01 & .03 & & & .06 & \\
Drunk & & .06 & .03 & & .13 & & .10 & & .02 \\
Booze & & .12 & .11 & .01 & .21 & .01 & .18 & .12 & \\
$\quad$ Sum & .34 & 1.23 & .48 & .20 & .80 & .16 & .80 & .68 & .23 \\
\hline
\end{tabular}

Note- $S\left(T_{i}\right)=\sum_{j=1}^{n}\left[S\left(T, A_{j}\right)+\sum_{i=1}^{n} S\left(A_{i}, A_{j}\right)\right]=.34+1.23+.48+.20+.80+.16+.80+.68+.23=4.92$, where

$\mathrm{S}=$ strength, $\mathrm{T}=$ target, $\mathrm{A}=$ associate.

the target and its associates. Both cued recall and priming are the net results of connections that link the cue and the target together, relative to connections to competing associates that reduce the probability of producing the target. Producing the target after a study trial depends on how strongly its implicit representation has been activated relative to the strength of competing associates activated by the test cue and by the target. Put simply, the target must win the competition with competing associates for both recall and priming effects to be observed. Finally, the model assumes that the intersection involving implicitly activated associates is computed regardless of whether the test is explicit or implicit. Explicit recall instructions produce higher levels of target recovery than do implicit freeassociation instructions because the explicit representation is also recovered, not because of differences in what is calculated about the implicit representation.

Although word frequency has not been incorporated into the computation of priming in PIER 2, it was expected to affect priming, on the assumption that a study presentation should produce a larger relative increment in familiarity for low- than for high-frequency words (e.g., Nelson et al., 1998). This hypothesis rests on Jost's law (Boring, 1957, p. 375), which, in this context, predicts that the amount of target priming will be relative to its baseline frequency-for example, ef/(ef + bf $)$, where ef $=$ experimental frequency and $b f=$ baseline frequency (Hintzman, 1976; Mandler, 1980). Interestingly, frequency $(\log .5+$ frequency) and connectivity are uncorrelated features $(r=-.05, n=4,099$, for mean number of within-set connections per associate, and $r=.04$ for the connection strength index described in Table 1). Lowfrequency words are as likely to vary in connectivity as are high-frequency words.

In order to evaluate the priming expectations for connectivity and frequency, the participants studied words that varied in these features and were then provided with extralist prime cues. One group was given free-association instructions, and another was given cued-recall instruc- tions at test. The participants in both groups were given cues for nonstudied targets, as well as for studied targets, in order to calculate within-experiment priming effects. On the assumption that the implicit representation contributes regardless of test instructions, both frequency and connectivity effects were predicted to have similar effects for each test instruction. However, priming effects were expected to be greater for explicit cued-recall instructions, because such instructions are more likely to recover the target's explicit representations, as well as its implicit representation.

\section{Method}

Design and Participants. The design formed a $2 \times 2 \times 2 \times 2$ mixed-model factorial in which test instructions (implicit, explicit) and target frequency (low, high) were varied between subjects. Both connectivity (low, high) and prior study (studied, nonstudied) were varied within list and, hence, within subjects. Twenty-four participants were assigned to the four between conditions (12 to each list). All were drawn from courses in psychology, received extra credit for their participation, and were randomly assigned in replication blocks to conditions and lists in order of appearance.

Materials. The lists in Appendix A were derived from an unpublished explicit cued-recall study on frequency and connectivity, which showed that each variable had reliable additive effects on recall. Each list in that study consisted of 24 cue-target pairs, and testing was for studied targets only. Because of the need for studied and nonstudied cues in this experiment, the plan was to merge the cues for the two lists during testing. This merger, however, could not be realized in full because of preexisting associations among one or two words across lists. Eliminating these items reduced the study lists to 22 targets for each frequency list, with half of the targets representing high-connectivity words and half representing low-connectivity words.

When target frequency was low, words occurred an average of 5 $(S D=4)$ times per million words, and when it was high, words occurred an average of $293(S D=294)$ times per million (Kučera \& Francis, 1967). Similarly, when target connectivity was low or high, each associate was connected to an average of 0.64 associates in the set $(S D=0.16)$ or 2.95 associates in the set $(S D=0.67)$, respectively. Activation strength computed according to the algorithm described in Table 1 averaged $1.48(S D=0.45)$ and $4.22(S D=1.17)$ for low- and high-connectivity words. Connectivity was equated at each level of frequency, and other variables were carefully controlled for each combination of frequency and connectivity. The means for cue and target 
set size were, respectively, $13.19(S D=3.92)$ and $13.43(S D=4.87)$; for rated concreteness, the values were $4.70(S D=1.40)$ and 4.92 $(S D=1.38)$. Probability of a resonant associate-to-targ et connection was also controlled at $.23(S D=.21)$. Most important, forward, backward, mediated, and shared associate strengths were also held constant and averaged, respectively, $.13(S D=.04), .06(S D=.03), .04$ $(S D=.02)$, and $.03(S D=.04)$. Regardless of the level of frequency and connectivity, forward, backward, and indirect connections were relatively weak.

Procedure. For the study trial, the participants were asked to read each word aloud when it was shown and to remember as many words as possible, without being told how they would be tested. The words were presented one at a time at a 3 -sec rate on a computer screen. Immediately following the study trial, the test instructions were read to the participants. The implicit test instructions indicated that we were collecting some free-association norms prior to the memory test for the words just studied. As each word was shown, the participants were asked to read it aloud and, as rapidly as possible, to produce the first meaningfully related or associated word that came to mind. The explicit test instructions stated that the cues were going to be presented one at a time and that some of the cues would be related to the studied words and that others would not be related. After reading the cue aloud, the participants were asked to use it to recall a related word from the study list and, if they could not think of one, to free associate the first word to come to mind that was related to the cue. The first 5 cue words shown were buffers that were unrelated to any target word. For both test conditions, one half of the 44 cue words were taken from the alternate target list, and one half were related to the target list just studied. For example, if List 1 targets were studied, the cues for List 1 targets were shown and randomly intermixed with the cues for List 2 targets. This procedure produced a prior study manipulation that could be used for collecting norms for the prime cues. Forward strength values for the unstudied cues were expected to be equivalent to those obtained in the free-association norms used for constructing the lists. Finally, the item sequences were unsystematically varied for both study items and test cues, and those receiving implicit test instructions were given a free-recall test for the study list following the free-association test. The test trial for both groups was self-paced.

\section{Results and Discussion}

Table 2 presents the mean probabilities of target recovery as a function of target frequency, target connectivity, test instructions, and prior study. A preliminary statistical analysis of target recovery for the nonstudied targets indicated that the chances of guessing the target were unaffected by frequency, connectivity, and instructions. None of the main effects and interactions involving these variables approached conventional levels of significance. The prob- ability of guessing the target averaged .12 across conditions, and this value closely approximated forward strength obtained in the free-association norms (.13). This result suggests that the differential nature of the test instructions did not affect the probability of guessing the target.

Priming effects were assessed by computing the difference scores obtained by subtracting probability of target production in the unstudied conditions from probability of production in the comparable study conditions. Comparisons of the priming scores for each condition indicated that the results conformed to expectations. As can be seen in Table 2, priming was greater for low- than for highfrequency words. It was also greater for high- than for lowconnectivity words and for explicit than for implicit test instructions. The results of an analysis of variance (ANOVA) indicated that priming varied significantly with test instructions $\left[F(1,92)=29.54, M S_{\mathrm{e}}=0.049\right]$, target frequency $[F(1,92)=30.19]$, and target connectivity $\left[F(1,92)=12.44, M S_{\mathrm{e}}=0.023\right]$. More targets were recovered under explicit instructions (.31) than under implicitinstructions (.14), more were recovered when target frequency was low (.30) than when it was high (.14), and finally, more were recovered when target connectivity among the associates was high (.26) than when it was low (.19). None of the interactions involving these three sources produced statistically reliable effects, including the test instructions $\times$ connectivity interaction $[F(1,92)=1.82]$. Connectivity effects were numerically smaller for implicit than for explicit test instructions, but this trend was not reliable.

The participants recovered more targets when asked to do so than when left to free-associate any related word. Explicit instructions to recall the studied words are more likely to lead to recovering the explicit representation. The context cue is utilized to recover the target under explicit test instructions, but not under implicit test instructions (Humphreys et al., 2000). More important, the participants were more likely to recover less frequently occurring words and words having greater numbers of connections among their associates. Although frequency effects represent a new priming phenomenon for the free-association task, connectivity effects have been found previously with the process dissociation procedure. High connectivity facilitated target recovery for both recollective and automatic

Table 2

Probability of Target Recovery as a Function of Target Frequency, Target Connectivity, Test Instructions, and Prior Study

\begin{tabular}{|c|c|c|c|c|c|}
\hline \multirow[b]{2}{*}{ Instructions } & \multirow[b]{2}{*}{$\begin{array}{l}\text { Prior } \\
\text { Study }\end{array}$} & \multicolumn{2}{|c|}{ Low Frequency } & \multicolumn{2}{|c|}{ High Frequency } \\
\hline & & $\begin{array}{c}\text { High } \\
\text { Connectivity }\end{array}$ & $\begin{array}{c}\text { Low } \\
\text { Connectivity }\end{array}$ & $\begin{array}{c}\text { High } \\
\text { Connectivity }\end{array}$ & $\begin{array}{c}\text { Low } \\
\text { Connectivity }\end{array}$ \\
\hline \multirow[t]{3}{*}{ Implicit test } & studied & .33 & .28 & 20 & .16 \\
\hline & nonstudied & .09 & .10 & .12 & .11 \\
\hline & priming & .24 & .18 & .08 & .05 \\
\hline \multirow[t]{3}{*}{ Explicit test } & studied & .57 & .45 & .37 & .29 \\
\hline & nonstudied & .08 & .11 & .14 & .11 \\
\hline & priming & .49 & .34 & .23 & .18 \\
\hline
\end{tabular}


uses of memory after semantic processing during study, but not after nonsemantic processing (Nelson, McKinney, \& Bennett, 1999).

The effects of both frequency and connectivity on priming were obtained even though both forward and backward strengths linking the cue-target pairs were held constant. As such, these results provide support for the target accessibility hypothesis. Studying the target increases its accessibility to related cues under explicit as well as implicit testing conditions, and given frequency and connectivity effects, at least some of this accessibility should be attributed to the implicit representation of the target as activation in LTWM. Low-frequency words and high-connectivity words appear to produce higher levels of target activation.

\section{EXPERIMENT 2}

The results of Experiment 1 provide support for the hypothesis that studying a word primes its representation as an independent entity, and the purpose of Experiment 2 was to do the opposing experiment. Target accessibility was held constant, and the presence of preexisting forward and backward connections was varied. Interest focused on three outcomes. First, if priming occurs under implicit testing only because of target accessibility (e.g., Chappell \& Humphreys, 1994), preexisting forward cue-to-target links should increase priming effects, and preexisting backward target-to-cue links should have no effects. Forward links should have an effect, because increasing a word's accessibility makes it more probable as a response to all related cues. Backward links should not have an effect, because they involve prior associations and the accessibility hypothesis has no provisions for accommodating such links.

Second, if priming occurs only because of target-to-cue association, forward links should have no effect, because target accessibility is not an issue. Only backward targetto-cue links should affect priming, in accordance with expectations based on the encoding specificity principle (Humphreys et al., 1989; Storms, 1958; Zeelenberg et al., 1999). Third, if priming occurs because of both target accessibility and target-to-cue association, priming will be increased by the presence of both forward and backward links. An effect of prior forward links would indicate that targets are more accessible to cues that normally produce them, and an effect of backward links would be indicative of the priming of a specific prior connection. Given the results of Experiment 1 and the results of Zeelenberg et al., this outcome seemed the most likely. This outcome would also be consistent with predictions derived from PIER 2.

In Experiment 2, these alternatives were evaluated directly by varying the presence of preexisting forward and backward connections in a factorial design. These manipulations were also crossed with number of study trials. PIER 2 attributes priming effects in implicit tests to recovery of the target's implicit representation, and in the absence of attention switching during study or prior to test, it predicts that a second study trial will have no effect on prim- ing. In contrast, in the Matrix model (Humphreys et al., 1989), priming occurs only when the connections among the studied word and its potential cues are stored as episodic representations. In the auto-associative model (Chappell \& Humphreys, 1994; Humphreys et al., 2000), a second study trial strengthens episodic intraitem information. Both models predict that a second study experience will increase priming, because repetition strengthens episodic associations in these models, although such effects are typically not found (see Humphreys et al., 2000).

\section{Method}

Design and Participants. The experimental design formed a $2 \times$ $2 \times 2 \times 2$ mixed-model factorial. Forward cue-to-target connections (present, absent), backward target-to-c ue connection s (present, absent), and number of study trials (one, two) were manipulated between subjects. Prior study (studied, nonstudied) was varied within subjects. Sixteen participants were assigned to each of the eight between-subjects conditions, with 8 assigned to List 1 and 8 assigned to List 2 . All received extra credit for their participation and were randomly assigned in replication blocks to conditions and lists.

Materials. Two lists, each consisting of 24 targets and 4 cues per target were constructed by selecting items from the association norms (see Appendix C in Nelson et al., 1998). The targets were held constant (e.g., CLOSET), and the manipulation s of preexisting strength were implemented by varying the selection of the test cues. One cue for each target was connected in both forward and backward directions (HANGER), one was connected in the forward, but not in the backward, direction (BROOM), one was connected in the backward, but not in the forward, direction (DOOR), and one was not connected at all according to the free-association measure (EXIT). Regardless of direction, connection strength averaged $.13(S D=.06)$ for preexisting connections and .00 for absent connections according to free association norms (Nelson, McEvoy, \& Schreiber, 1999). This means that, respectively, approximately 20 out of 150 people produced the target in free association when a connection was present and 0 out of 150 people produced the target when the connection was absent. When connections were present, they were weaker relative to those selected by Zeelenberg et al. (1999; about .25) in order to avoid using primary associates. Primary associates could limit the magnitude of the priming effects because the baseline probabilities tend to be so high.

Indirect connections between the test cues and the targets were held constant in the four conditions. Regardless of the strengths of the forward and backward connections, test cues shared an average of 1.42 associates $(S D=1.07)$ and 0.95 mediated connections $(S D=$ $0.95)$ with their targets. Although not all pairs were directly connected according to the normative database, all were about equally and weakly related in terms of indirect connections. Cue set size was held constant, with each cue averaging 13.87 associates $(S D=$ 4.85 ), with cue frequency averaging 120 words per million $(S D=$ $220)$. Target set size and target frequency values were similar in magnitude, averaging 14.50 associates $(S D=4.41)$ and 79 words per million ( $S D=107)$, respectively. Finally, the mean numbers of resonant connections to the target from its associates and the mean numbers of connections among the target's associates averaged 6.15 $(S D=3.12)$ and $1.41(S D=0.64)$.

Procedure. During the study trial, the participants were asked to rate the study words for pleasantness, as in the Zeelenberg et al. (1999) study, so the items were encoded under incidental, instead of intentional, learning conditions. In individual sessions, the participants were told that we were collecting pleasantness norms for familiar words and that we were asking them to rate words for pleasantness on a 5-point scale, with a rating of 5 indicating very pleasant and a rating 
of 1 indicating very unpleasant. Each target was shown individually on a computer screen for $3 \mathrm{sec}$; the participants read it aloud when it was shown and provided their rating by calling out a number rating of $1-5$. Finally, for those receiving a second presentation, the targets were presented again in a different random order, and each item was rerated on pleasantness prior to the free-association trial.

Immediately following the last study word, the participants were told that we were collecting free-association norms in the second part of the study. As each word was shown, they were asked to read it aloud and, as rapidly as possible, to produce the first meaningfully related or associated word that came to mind. The first five cue words shown were buffers that were unrelated to any target word. As in Experiment 1 , one half of the cue words in the free-association task (now, $n=48$ ) were taken from the alternate target list, and one half were related to the target list just rated for pleasantness; these cues were randomly intermixed. The free-association trial was self-paced, and the orders of appearance of both study and test words were independently and unsystematically randomized for each participant.

\section{Results and Discussion}

Probability of target recovery as a function of forward strength, backward strength, prior study, and number of study presentations is shown in Table 3 . The priming scores are shown in the middle and bottom rows of the table. As can be seen, priming was largest when both forward and backward connections were present, next largest when either connection was present, and nonexistent when neither connection was available. Number of study presentations had little or no effect. The results of a $2 \times 2 \times 2$ ANOVA indicated that only two sources were significant. Priming was greater when forward cue-to-target connections were present $(.14)$ than when they were not $[.02 ; F(1,120)=61.22$, $\left.M S_{\mathrm{e}}=0.007\right]$ and when backward connections were present $(.11)$ than when they were not $[.05 ; F(1,120)=19.42]$. Although priming effects appeared to be greater when both connections were present, the interaction between these sources was not significant $[F(1,120)=2.34]$. A Fisher's two-tailed least significant difference (LSD) of .03 indicated that all four conditions were different from each other. Finally, number of presentations had no effect $(F<1)$, and all remaining sources of variance produced $F \mathrm{~s}<1$.

Performance in the nonstudied baseline condition was lower than expected on the basis of the normative data (.13) for the forward only conditions (.09), but particularly for the backward only conditions (.04), perhaps because of regression to the mean. The natural correlation between for- ward and backward strength was not reduced to zero in building the lists $(r=.05, n=192)$, so the data for this experiment were also analyzed in a multiple regression analysis that controls this relationship statistically. Given that the same words served as studied and nonstudied items, a priming score could be constructed for each item, with the data pooled over participants. The results of the multiple regression analysis showed that the regression was significant $\left[F(2,189)=27.12, M S_{\mathrm{e}}=3.01\right]$, with forward and backward connections correlated $(R=.47)$ with priming scores. The standardized beta coefficients for forward and backward links were, respectively, $.38(t=5.95)$ and $.26(t=4.04)$. Forward and backward links each significantly affected the magnitude of priming when the correlation between forward and backward strengths was statistically controlled. Hence, each link affected priming in the item-based analysis, where the correlations between forward strength and backward strength with priming were $r=.40, p<.0001$, and $r=.28, p<.0001$, respectively.

These results indicate that naming the target and rating it for pleasantness primed preexisting connections to the word serving as a prime cue for free association. Priming was obtained whenever the target held a preexisting back connection to the cue, as would be predicted by the target association hypothesis, as well as by other approaches (e.g., Humphreys et al., 1989; Nelson et al., 1998; Tulving $\&$ Thomson, 1973). Furthermore, priming effects were also apparent when there were preexisting links in the forward direction, a result that is consistent with expectations derived from the target accessibility hypothesis. These findings indicate that priming is produced by increased target accessibility and by prior target-to-cue links. As was predicted by PIER 2, evaluating the target for pleasantness primed the target's accessibility, as well as the target-tocue connections, and each of these influences added to the overall level of observed priming.

In the present experiment, priming was obtained even when only a forward cue-to-target connection was present, and this condition produced a somewhat larger priming effect than when only a backward target-to-cue link was present. This finding did not replicate the findings of Zeelenberg et al. (1999). We do not know why this difference emerged, but it could be related to their use of different target words for the two priming conditions evaluated in their

Table 3

Probability of Target Recovery as a Function of Forward Strength, Backward Strength, Number of Presentations, and Prior Study After Pleasantness Ratings

\begin{tabular}{|c|c|c|c|c|c|}
\hline \multirow[b]{2}{*}{ Presentations } & \multirow[b]{2}{*}{$\begin{array}{l}\text { Prior } \\
\text { Study }\end{array}$} & \multicolumn{2}{|c|}{ High Forward } & \multicolumn{2}{|c|}{ Low Forward } \\
\hline & & $\begin{array}{c}\text { High } \\
\text { Backward }\end{array}$ & $\begin{array}{c}\text { Low } \\
\text { Backward }\end{array}$ & $\begin{array}{c}\text { High } \\
\text { Backward }\end{array}$ & $\begin{array}{c}\text { Low } \\
\text { Backward }\end{array}$ \\
\hline \multirow{3}{*}{ One } & studied & .32 & .17 & .09 & .00 \\
\hline & nonstudied & .14 & .09 & .04 & .00 \\
\hline & priming & .18 & .08 & .05 & .00 \\
\hline \multirow[t]{3}{*}{ Two } & studied & .33 & .18 & .08 & .00 \\
\hline & nonstudied & .15 & .09 & .04 & .00 \\
\hline & priming & .18 & .09 & .04 & .00 \\
\hline
\end{tabular}


experiments. In the present study, the same target was used in all the priming conditions. As Experiment 1 has shown, target characteristics can affect the magnitude of priming effects. Alternatively, they may have failed to find priming effects in the forward only condition because their cue-target pairs were much stronger than those used here. Priming effects occurring as a result of increased target accessibility may be reduced when the target is already highly accessible as a primary response to the cue used to prompt its recovery.

Providing a second study trial produced no additional priming (see also Humphreys et al., 2000). This null result is interesting because it is contrary to what is found under cued-recall instructions under similar conditions (Humphreys et al., 2000; Schreiber \& Nelson, 1998). The contrast suggests that the implicit free-association testing procedure used here was not contaminated by intentional recall. According to PIER 2, a second study trial on the target strengthens its explicit representation and has only negligible effects on the strength of its implicit representation. Activation is maintained until conceptually based attention has been switched to another cognitive task, such as naming vowels during study or doing complex multiplication immediately after study (Nelson et al., 1998). Since neither type of attention switch was present in this experiment, the second study trial had no effect.

\section{EXPERIMENT 3}

Experiment 3 was linked to Experiment 2 in that the only known difference was that the participants were given intentional learning instructions instead of pleasantnessrating instructions prior to the study trial. Weaker priming effects were expected for the intentional learning instructions than for the ratings. Pleasantness ratings focus conceptual processing directly on each target as an individual unit in memory, whereas intentional instructions tend to encourage the rehearsal of subgroups of items. Under intentional instructions, conceptual attention is focused on developing episodic links, and to the extent that this focus diverts attention away from the study word as an independent unit, PIER 2 predicts a reduction in priming. Switching attention during study theoretically reduces the accessibility of the implicit representation.
There is a notable weakness in the evaluation of this prediction, however. Reduced priming effects for intentional instructions could occur because intentional instructions produce weaker explicit representations of the targets, as compared with ratings. The explicit representation is not supposed to contribute to priming effects in the implicit free-association test, but independent ensurance is needed to reject the possibility that the test is contaminated by intentional recall. Hence, as in Experiment 2, number of study trials was varied as a manipulation check. If number of study trials has no effect, differences in priming obtained for intentional learning and pleasantness ratings can reasonably be attributed to differences in the relative strength of the implicit representation, as opposed to differences in the strength of the explicit representation.

\section{Method}

Design, Materials, and Procedures. The design, materials, and other procedures were identical to those used in Experiment 2. The study instructions for intentional learning were identical to those used in Experiment 1, and 20 participants were assigned to each betweensubjects condition.

\section{Results and Discussion}

The results are shown in Table 4, and as can be seen, the pattern of priming effects is similar to that found for pleasantness ratings. Priming effects tended to be greater when forward connections were present (.08) than when they were absent (.03) and when backward connections were present (.07) than when they were absent (.03). Both of these effects were reliable, with respective $F_{\mathrm{s}}(1,152)$ of 12.36 and $6.95\left(M S_{\mathrm{e}}=0.007\right)$. Number of study trials appeared to have a weak effect when both forward and backward links were present, but number of study trials was not reliable $[F(1,152)=1.25]$, nor did any of the interactions approach the criterion for significance.

An ANOVA of the combined data for Experiments 2 and 3 that included study instructions as a variable confirmed the effectiveness of both forward $[F(1,272)=66.61$, $\left.M S_{\mathrm{e}}=0.007\right]$ and backward $[F(1,272)=25.36]$ connections. This analysis also indicated that the overall priming effect was larger for ratings (.08) than for intentionallearning (.05), and although the difference was small, it was significant $[F(1,272)=6.24]$. Moreover, the interaction between study instructions and the presence of forward links

Table 4

Probability of Target Recovery as a Function of Forward Strength, Backward Strength, Number of Presentations, and Prior Study After Intentional Learning Instructions

\begin{tabular}{|c|c|c|c|c|c|}
\hline \multirow[b]{2}{*}{ Presentations } & \multirow[b]{2}{*}{$\begin{array}{l}\text { Prior } \\
\text { Study }\end{array}$} & \multicolumn{2}{|c|}{ High Forward } & \multicolumn{2}{|c|}{ Low Forward } \\
\hline & & $\begin{array}{c}\text { High } \\
\text { Backward }\end{array}$ & $\begin{array}{c}\text { Low } \\
\text { Backward }\end{array}$ & $\begin{array}{c}\text { High } \\
\text { Backward }\end{array}$ & $\begin{array}{c}\text { Low } \\
\text { Backward } \\
\end{array}$ \\
\hline \multirow[t]{3}{*}{ One } & studied & .26 & .19 & .09 & .01 \\
\hline & nonstudied & .20 & .13 & .04 & .00 \\
\hline & priming & .06 & .06 & .05 & .01 \\
\hline \multirow[t]{3}{*}{ Two } & studied & .24 & .17 & .08 & .00 \\
\hline & nonstudied & .13 & .10 & .02 & .00 \\
\hline & priming & .11 & .08 & .05 & .00 \\
\hline
\end{tabular}


was significant $[F(1,272)=11.99]$. For ratings, priming scores of .13 and .02 were found when forward links were present and absent, respectively. In contrast, for intentional learning, these scores were .08 and .03. A Fisher's LSD of .03 indicated that significant priming effects were found in each instructional condition, so the interaction indicated a difference of degree, rather than of kind. The study instruction $\times$ presence of backward links interaction showed a similar pattern for mean priming scores, but it was not reliable $[F(1,272)=1.28, p<.13]$. Importantly, number of study trials had no effect in the analysis of the pooled data, nor did any of its interactions with the other sources approach the criterion for significance. None of the remaining interactions approached this criterion.

The analysis of the pooled data confirmed the results of the individual experiments and showed that priming was somewhat greater after pleasantness ratings than after intentional learning instructions when forward links between the cue and the target were present. Although the differences produced by instructions were small, they suggest that focusing on the task of creating episodic links during study reduces the accessibility of the target. Because a second study trial had no effect on priming, this reduction is more likely to be due to the contribution of the implicit, rather than the explicit, representation.

\section{EXPERIMENT 4}

The results of Experiments 1-3 indicate that processing a target primes both its representation and target-toassociate links, and they are consistent with expectations based on the target accessibility and target association hypotheses. The purpose of Experiments 4 and 5 was to determine whether similar results would hold for indirect connections. Indirect connections can be classed into two types: shared associates (both SONG and CHORUS produce music as associates) and mediated associates (SPOON to knife to UTENSIL). Under cued-recall conditions, each type of indirect connection increases probability of correct recall (Nelson, Bennett, \& Leibert, 1997; Nelson et al., 1998). In Experiment 4, the presence of prior shared associate links was crossed with the presence of prior mediated links at high and low levels. If indirect links contribute to priming effects, the results should resemble the pattern found for direct connections. According to PIER 2, priming effects will be greater when prior indirect connections are strong than when they are weak. Both types of indirect connection were investigated after pleasantness ratings (Experiment 4) and after intentional learning instructions (Experiment 5).

The model predicts that shared associates will contribute to priming because the target activates them during study and the cue activates them during test. For example, studying CHORUS activates music and primes the link connecting these items. If the test cue SONG also activates music, the prior activation of music will facilitate the recovery of CHORUS. Priming will benefit from the indirect
SONG-to-music and CHORUS-to-music links. In this model, any associate that is activated by the target during study is predicted to benefit target recovery regardless of whether it serves as the test cue or as a shared associate. With this principle in mind, note that differential priming effects that are due to the prior activation of preexisting target-toassociate links should not be found for mediated connections. For mediating links such as SPOON-knife- UTENSIL, the mediator knife is unlikely to be activated during study by UTENSIL according to normative data, so it is unlikely to be primed. In the model, mediated links contribute because, like forward strength, they can increase target accessibility.

\section{Method}

Design and Participants. The design formed a $2 \times 2$ factorial, with both shared associate strength (strong, weak) and mediated strength (strong, weak) varied within subjects. Two lists were created, and 15 participants were assigned to each list, using the procedures of Experiment 1. This assignment produced 30 participants in each test condition, and they were selected from the same sources as those who participated in Experiment 1.

Materials. The two lists of cue-target pairs used in this experiment are available in Appendix B. Mediated strength was calculated by multiplying the probability that the test cue produces the mediator in free association by the probability that the mediator produces the target in free association. The results were then summed when more than a single mediator was involved for a single pair (see Nelson, Bennett, \& Leibert, 1997). When mediated strength was high, strength averaged $.20(S D=.05)$, and the number of mediated connections between each pair averaged $3.71(S D=2.12)$. When mediated strength was low, these means were $.002(S D=.003)$ and $1.00(S D=1.18)$. Shared associate strength was calculated by multiplying the probability that the cue produces the shared associate by the probability that the target produces the same associate, with the results summed when more than a single shared associate was involved. When shared associate strength was high, it averaged $.22(S D=.06)$, and the number of shared connections per pair was $2.75(S D=1.15)$. When low, these values were $.003(S D=.010)$ and $1.29(S D=1.30)$.

Other materials variables were controlled for each condition of strength. All of the cues had relatively weak forward connections to their targets, averaging $.10(S D=.06)$, so priming because of target accessibility was expected in all the conditions. However, few targets had back connections to their cues. Fifty-eight percent of the targets showed no measured back connection to their cues, and mean back connection strength averaged .02 pooled over all items $(S D=.04)$. Hence, the words serving as test cues were not likely to have been encoded during the study trial. Cue and target set size averaged 9.75 $(S D=3.35)$ and $12.33(S D=3.47)$ associates, respectively. Means for cue and target frequency, concreteness, and connectivity were 85 $(S D=87)$ and $87(S D=86), 4.89(S D=1.31)$ and $4.03(S D=$ $0.49)$, and $2.13(S D=3.01)$ and $1.28(S D=0.31)$, respectively. Hence, the cues normally produced the targets at relatively low rates in free association, and the items generally fell within the middle ranges on set size, frequency, concreteness, and connectivity.

Procedure. The procedures were identical to those used in Experiment 2 , including the use of the incidental pleasantness-rating task during study. During the implicit free-association test, the participants were asked to read the cue aloud and then produce the first related word to come to mind as rapidly as possible. The first five cues consisted of buffers, and the next 48 cues consisted of 24 cues for the studied target list randomly intermixed with the 24 cues for the nonstudied list. 
Table 5

Priming Effects as a Function of Mediated Strength and Shared Associate Strength for Experiment 4 (Pleasantness Ratings) and Experiment 5 (Intentional Learning)

\begin{tabular}{|c|c|c|c|c|}
\hline \multirow[b]{2}{*}{$\begin{array}{l}\text { Prior } \\
\text { Study }\end{array}$} & \multicolumn{2}{|c|}{$\begin{array}{c}\text { High Shared } \\
\text { Associate Strength }\end{array}$} & \multicolumn{2}{|c|}{$\begin{array}{c}\text { Low Shared } \\
\text { Associate Strength }\end{array}$} \\
\hline & $\begin{array}{l}\text { High Mediator } \\
\text { Strength }\end{array}$ & $\begin{array}{l}\text { Low Mediator } \\
\text { Strength }\end{array}$ & $\begin{array}{l}\text { High Mediator } \\
\text { Strength }\end{array}$ & $\begin{array}{c}\text { Low Mediator } \\
\text { Strength } \\
\end{array}$ \\
\hline \multicolumn{5}{|c|}{ Experiment 4 (Pleasantness) } \\
\hline Studied & .29 & .26 & .24 & .18 \\
\hline Nonstudied & .12 & .05 & .12 & .12 \\
\hline Priming & .17 & .21 & .12 & .06 \\
\hline \multicolumn{5}{|c|}{ Experiment 5 (Intentional) } \\
\hline Studied & .30 & .23 & .28 & .21 \\
\hline Nonstudied & .18 & .10 & .20 & .09 \\
\hline Priming & .12 & .13 & .08 & .12 \\
\hline
\end{tabular}

\section{Results}

The results are shown in the top portion of Table 5, and as can be seen, priming effects were influenced by shared associates, but not by mediated associates. Priming for shared associates averaged .19 for strong prior connections and .08 for weak connections, and priming for mediated associates averaged .14 for strong links and .13 for weak links. A repeated measures ANOVA indicated that shared associates significantly affected priming $[F(1,29)=7.98$, $\left.M S_{\mathrm{e}}=0.047\right]$ and that neither mediated associates $(F<1)$ nor the interaction of these variables $(F=1.42)$ was significant.

A separate ANOVA of these data that included prior study as a variable indicated that rating the targets for pleasantness significantly increased the probability that that they would be recovered in the free-association task $\left[F(1,58)=26.54, M S_{\mathrm{e}}=0.044\right]$. The probability that studied targets would be produced was .24 , whereas the probability that nonstudied targets would be produced was .10 , a value that approximated the normative probabilities. All of the test cues in this experiment held direct forward connections to their targets, and an overall priming effect is consistent with earlier results showing that studying the target increases its accessibility to all related cues.

\section{EXPERIMENT 5}

The main purpose of Experiment 5 was to determine whether the differential priming effects associated with shared associates in Experiment 4 would be apparent under intentional learning instructions after a single study trial. As was noted earlier in this article, intentional learning instructions tend to turn participants away from encoding the target as an independententity and toward encoding it as a member of an episodic unit. Another purpose of this experiment was to determine whether the absence of differential priming effects for mediating associates in Experiment 4 was due to problems with the materials. As a manipulation check, a separate group of participants was given standard cued recall instructions. If mediated associates were effectively manipulated in these materials, cued-recall probability would vary with both shared associate strength and with mediated associate strength.

\section{Method}

Design and Participants. The design for the priming portion of the experiment formed a $2 \times 2$ repeated measures factorial, with both shared associate strength and mediated associate strength varied within subjects, as in Experiment 4. Forty participants were assigned to this design, with 20 assigned to each of the two lists. The design for the cued-recall portion of the experiment also formed a $2 \times 2$ repeated measures factorial of the same variables, and 40 different participants were assigned to it in a like manner.

Materials and Procedure. The materials were the same as those in the previous experiment, as were the general procedures, except for the study and test instructions. Prior to the study trial, all the participants were asked to remember as many words as possible, without being told how they would be tested. Just prior to test in the extralist cued-recall condition, they were told that words would be presented as cues for the studied words and that they were to use each cue to recall one of the targets. Examples were used to clarify the instructions, and as is usual in this task, cues for nonstudied targets were not shown. In contrast, the participants in the free-association test were told that, before testing their memory for the words just seen, we wanted to collect free-associations norms. The procedure was explained, and as before, the participants were asked to read the cue aloud and then produce the first related word to come to mind as rapidly as possible. The first 5 cues consisted of buffers, and the next 48 cues consisted of randomly intermixed words that were either related to the study words or not. Following the free-association test, all the participants were asked to free-recall the target words but since these data were irrelevant to the purpose of the study, the results will not be presented.

\section{Results and Discussion}

The bottom portion of Table 5 presents the priming effects. An overall priming effect was evident, and an analysis with prior study as a separate variable indicated that the participants were more likely to produce studied targets (.25) than nonstudied targets (.16) in free association $\left[F(1,19)=19.84, M S_{\mathrm{e}}=0.016\right]$. However, the evidence for differential priming effects was very weak. The priming effect for shared associates was higher when connection strength was stronger, but this difference was small. An ANOVA of the priming scores indicated that shared associate strength, mediated associate strength, and the interaction of these sources each produced $F_{\mathrm{S}}<1$.0. However, 
when the results from Experiments 4 and 5 were combined, the shared associate effect was reliable $[F(1,68)=8.12$, $\left.M S_{\mathrm{e}}=0.039\right]$. No other sources had significant effects, including study instructions. However, reflecting the trends in Table 5, the study instructions $\times$ shared associate strength interaction approached significance $[F(1,68)=$ $2.92, p<.09 ; \mathrm{LSD}=.07]$. After pleasantness ratings, the pooled priming effects for high and low shared associate strengths were, respectively, .19 and .08 , whereas after learning instructions, these values were .13 and .10 . Shared associates increased the magnitude of the priming effect, and this effect was numerically larger after the target was rated for pleasantness.

As in Experiment 4, mediated strength failed to have any effects on implicit free association. This failure, however, apparently was not the result of a materials problem. The cued-recall manipulation check showed that the probability of cued recall was greater when shared associate strength was high (.62) than when it was low (.52), and similarly, it was greater when mediated strength was high (.64) than when it was low (.50). An ANOVA indicated that both shared associate strength $[F(1,39)=$ $\left.14.98, M S_{\mathrm{e}}=0.026\right]$ and mediated strength $[F(1,39)=$ $\left.24.70, M S_{\mathrm{e}}=0.03\right]$ had significant effects. The respective means for the high-high, high-low, low-high, and low-low conditions were $.70, .53, .58$, and .46 .

The results of Experiments 4 and 5 indicated that shared associate connections increased implicit priming effects, whereas mediated connections did not. The failure to find a mediated priming effect was not due to problems with materials, because such effects were found with extralist cued-recall instructions. This failure is inconsistent with PIER 2's predictions, and the reasons for it are unclear. For unknown reasons, the baseline probabilities for mediated connections tended to be higher and less stable than was expected on the basis of the normative data. Alternatively, mediated connections may contribute to performance on an "as needed" basis. The goal of free association is to produce the first related word to come to mind, and this goal may have been easily achieved on the basis of the forward connection alone, without the need to compute mediated connections. In Experiments 4 and 5, all cues had weak forward connections to their targets, and this link may have been sufficient for achieving the goal of recovering any related word. In contrast, the goal of cued recall is to produce a specific word, the studied target, and the system may compute both direct and indirect links in order to achieve this goal. However, even in cued recall, the findings show that the effects of both shared and mediated associates are reduced when the test cue has a strong direct connection to the target (Nelson, Bennett, \& Leibert, 1997). The computation of indirect connections may be influenced by the goal set for the retrieval process and by the strength of the test cue in relation to that goal. If secondary connections are computed on a selective "as needed" basis, PIER 2's assumption that all cue-target links are automatically computed will need to be modified.

\section{GENERAL DISCUSSION}

The present experiments indicate that priming was affected by target characteristics. Low-frequency words and words having more connections among their associates showed greater priming effects than did high-frequency words and those with fewer connections among their associates. These effects were observed even though the strengths of the forward cue-to-target and backward targetto-cue connections were controlled, and they were consistent with earlier findings on target characteristics showing that target set size also influenced priming (Nelson, Bennett, \& Xu, 1997; Nelson et al., 1992). In those studies, targets with smaller sets of associates produced greater priming effects than did targets with larger sets of associates. Hence, studied targets that are low in frequency, that have dense connections among their associates, and that have relatively smaller associative sets were more likely to be recovered on an implicit free-association test. These variables have similar effects on explicit cued recall (Nelson et al., 1998; Nelson et al., 1992).

The present findings also indicated that priming is affected by the presence of both direct and indirect preexisting connections between the target and the associated words. Priming effects were greater when there was a direct connection from the target to an associate that served as the test cue than when the cue ostensibly was not a member of the target's set. Priming effects were also greater when there was a direct connection from the test cue to the target than when there was not. The presence of both forward and backward connections had additive effects on priming for the same target word. The forward connection added to the priming effects of the backward connection. Furthermore, priming effects for indirect connections involving shared associates were also found. For example, the test cue SONG and the target CHORUS each produce music as an associate, and such links increased the probability of target recovery in the explicit cued-recall test and in the implicit free-association test. In contrast, mediating links emanating from the test cue (e.g., SPOON to knife to UTENSIL) affected cued recall but had no effect on priming. Finally, priming effects produced by direct connections and, to a lesser extent, by shared associates were more apparent after pleasantness ratings than after intentional learning.

\section{Theoretical Implications}

Implications for theories of priming. These findings carry implications for theories of priming effects because they provide support for both the target accessibility and the target association hypotheses. The evidence favoring the accessibility hypothesis comes from findings related to variations of target characteristics and forward strength. The differential priming effects produced by the effects of target frequency, connectivity (Experiment 1), and set size (Nelson, Bennett, \& Xu, 1997; Nelson et al., 1992) indicate that studying a target increases its accessibility as a response to related words that produce it as an associate. As would be expected, the presence of a forward cue-to-target 
connection also increases priming, and this increase is somewhat more apparent after pleasantness ratings than after intentionallearning. Focused processing of the target as an independent unit in memory differentially increases priming, as compared with processing that is designed to link unrelated words episodically. Hence, studying a target word, especially as an independent unit, increases its accessibility to a related cue, and this increase is more apparent for words that are low in frequency, high in associative connectivity, and small in set size. Such findings cannot be explained by theories of priming that assume that priming is produced solely by preexisting target-to-cue connections (e.g., Humphreys et al., 1989; Storms, 1958).

Increases in accessibility related to frequency and associative connectivity arise because of theoretically higher target activation levels (e.g., Anderson, 1983; Horowitz \& Prytulak, 1969; Mandler, 1980; Nelson et al., 1998). Higher levels of activation increase the probability that the target will be recovered among the associates activated by the prime cue during the implicit free-association test (Nelson, McEvoy, \& Dennis, 2000). Although held constant in the present studies, the effects of set size on priming in earlier studies indicate that competition effects are apparent in the implicit free-association test (Nelson et al., 1998; Nelson et al., 1992). As in cued recall, the probability of selecting the target from its activated associates is greater when set size is small than when it is large. In any task involving prior study, the target must win the competition with its and the cue's competing associates. Moreover, higher levels of target activation also explain why the pleasantness task produces stronger priming effects than do intentional learning (Experiments 2 and 3 ) and nonsemantic processing (Vaidya et al., 1997; Weldon \& Coyote, 1996). Focusing attention on the target as an independent semantic unit presumably increases its activation strength as an implicit representation, as compared with when attention is focused on creating episodic links among unrelated list words or when attention is switched to nonsemantic features (Nelson et al., 1998).

The present findings provide support for the accessibility hypothesis, and they also provide support for the target association hypothesis. Priming effects were observed for backward target-to-cue and target-to-shared-associate links (Experiments 2-4; Storms, 1958; Zeelenberg et al., 1999). Such effects are attributed to increased activation levels, but the increase applies to connections to related words, rather than to target accessibility (e.g., Nelson et al., 1998). The facilitating effects of target-to-associate connections are, of course, inconsistent with accessibility theories that attribute priming solely to increased target accessibility (e.g., Anderson, 1983; Chappell \& Humphreys, 1994). The findings of the present experiments do not support the conclusion that priming is produced solely by target accessibility or solely by target association. Instead, priming is apparently influenced by each of these sources of information.

Only theories that allow for both the priming of the target and its links to its associates are capable of handling the present findings, and for the moment, only PIER 2 seems to posses this characteristic (Nelson et al., 1998). This model also explains why both target activation and target-to-cue activation contribute additively to priming effects, just as they contribute additively to cued recall. The retrieval equation associated with this model directly incorporates target priming into the calculation of net cue-target strength, in which the target-to-cue connection plays a prominent role. In PIER 2, target priming is affected by frequency, connectivity, and resonance (links to the target from its associates), and for the latter two variables, the amount of priming is determined by summing all of the pairwise connection strengths involving the target and its associates. This information, in turn, is fed directly into a second equation that computes net cue-target strength by cross-multiplying and summing the results across the associates that link the two words. Finally, the results of the second equation are fed into a third equation that computes the ratio of net cue-target strength relative to the competition produced by the nonlinking associates of the cue and the target. Competition for the target arises from associates of the test cue and from associates of the target that do not provide preexisting links between the two items.

More specifically, Equations 1 and 2 are illustrated in Appendix $\mathrm{C}$ for the target RUM cued by the word WHISKEY. As is illustrated in the top portion of Appendix C, Equation 1 assumes that free-association norms provide a baseline index of the likely activation levels for each pairwise connection for RUM's strongest associates. Encoding RUM activates its connections to associates in parallel, with some associates activated more strongly than othersfor example, coke at .28, drink at .16, and so on. In addition, the model assumes that encoding RUM simultaneously activates all pairwise links to its associates, from its associates (resonance), and among its associates (connectivity). The resonant activation from its associates increases the self-strength of the target from a nominal value of 1.0 to its primed value, which, for RUM, is 1.16. Connectivity among its associates primes the preexisting connection strengths from the target to each of its associates. The RUM-to-coke link increases from .28 to .34 , the RUMto-drink link increases from .16 to 1.23 , and so on. Connections among the representations making up any associative network strengthen the implicit representation of the target. The greater the number and the greater the prior strength of these connections, the higher the target activation will be. As is shown in Appendix C, the strength of the implicit representation of the target is determined by adding its nominal value to its primed resonance and primed connectivity values. Although not shown, the nominal self-strength of the target is theoretically affected by frequency of occurrence.

Equation 1 captures implicitly primed target strength through prior measurements of preexisting strength of the pairwise connections making up the target's set. ${ }^{2}$ This equation predicts that both resonance and connectivity will strengthen the implicit representation of the target and that these features will have additive, rather than interactive, ef- 
fects. The effects of connectivity are not contingent on the presence of resonant connections, so the model does not fit a spreading activation metaphor. Although resonant connections were held constant in these experiments, the effects of connectivity were apparent in the priming task, as they are in the extralist cuing task. The effects of both variables, however, are not manifested directly in the model. Their influence depends on the intersection of the test cue and its associates with the priming of the target and its associates.

Observing a priming effect depends on the intersection of connections that link the test cue with the target (Equation 2) relative to nonlinking connections activated by both the cue and its target (Equation 3 ). ${ }^{3}$ The importance of the linking connections is demonstrated in the bottom half of Appendix $\mathrm{C}$ with an example computation that uses the cue WHISKEY to recover the primed target RUM. The top row of the retrieval matrix presents the primed activations for RUM's self-strength and for its primed connections to its associates, as determined by Equation 1. The bottom row presents the normative activations for the test cue of only the connections that link the cue with the target-for example, the forward WHISKEY-to-rum and WHISKEY-todrink links, and so forth. Equation 2 computes net cuetarget strength by cross-multiplying the target's priming strengths by the baseline strengths activated by the cue for each linking connection and then summing the results. In this way, the quantities comprising resonance and connectivity, as well as the four indices of cue-target strength, are reduced to a single quantity.

Equation 2 makes these computations on the basis of the strengths of pairwise connections as indexed through free association, and as a consequence, it can be computed for the cue-target pairs used in the present experiment. In previous research, such computations indicated that Equation 2 predicted probability of extralist cued recall as well as when the variables were considered separately in multiple regression equations (Nelson \& Zhang, 2000). Similar success will be evident if Equation 2 predicts priming. To evaluate this prospect, a database was created from the five experiments reported here, and two multiple regression analyses were run. In the first, priming scores for each pair were computed, and frequency $[\log (.5+$ frequency)], connectivity, and the four indices of cue-target strength were included as the variables. The regression was significant $\left[R=.38 ; F(2,559)=15.52, M S_{\text {res }}=3.66\right]$, with five of six variables contributing significantly to the results. Both frequency and connectivity had significant effects, with standardized betas of $-.11(t=-2.81)$ and $.08(t=2.08)$, respectively. In addition, forward strength $(.19, t=4.71)$, backward strength $(.18, t=4.58)$, and shared associate strength $(.18, t=4.19)$ each had significant effects. As in the experiments, mediated strength was the only factor that failed to affect priming (beta $=.02, t=$ 0.38 ). In the second analysis, Equation 2 was substituted for these indices, and the resulting regression was also significant $\left[R=.34 ; F(2,563)=36.74, M S_{\text {res }}=3.75\right]$. Both frequency and Equation 2 were significant predictors of priming, with betas of $-.16(t=-4.08)$ and $.31(t=7.80)$. Equation 2 predicts priming about as effectively as when the variables were entered separately into the equation.

Equation 2 predicts resonance and connectivity effects because the primed strengths of the target's implicit representation are included in the calculation. It predicts backward target-to-cue and target-to-shared-associate priming because these links represent a part of the implicit representation. It also predicts forward cue-to-target effects because the effects of target priming, as measured by Equation 1 , are multiplied by the degree of forward strength in Equation 2. The model also makes several untested predictions. For example, it predicts that priming effects that are due to target frequency, resonance, and connectivity will be curtailed when the test cue has no forward link to the target. For example, if a forward strength of zero is entered for the WHISKEY-to-rum link in the example calculation of Equation 2 in Appendix C, the cross-multiplication will be zero no matter how strongly rum has been activated. Target frequency and resonance effects will not be evident, and connectivity effects will be evident only to the extent that target-to-shared-associate links have been primed.

The model also predicts that low-frequency words will produce stronger priming effects than will high-frequency words (Nelson et al., 1998), but this prediction has not as yet been incorporated directly into the calculation of Equation 1 (which is beyond the scope of this paper). This calculation could take different forms, but in the model, such forms would be incorporated into the target's self-strength. Furthermore, because the model assumes that the priming calculated in Equation 1 is susceptible to switches of conceptual attention both during and after study (Nelson et al., 1998), the model is capable of explaining why pleasantness ratings during study increase the influence of forward connections. Note, however, that although the model can be used to interpret this result, it does not predict it directly from its calculations. This aspect of the model awaits further development. Finally, the model predicts target set size effects and, although untested, cue set size effects, on the assumption that increases in the numbers of competing associates decrease target recovery (Equation 3). Target recovery is influenced by the ratio of linking connections to nonlinking connections whenever a specific word must be recovered out of the noise of the many lexical representations that have been activated.

Implications for explaining frequency effects. The present results also carry implications for explanations of frequency effects for two explicit tasks: recognition and extralist cued recall. In single-item recognition, lowfrequency words are more likely to be correctly recognized when studied and correctly rejected when they appear as lures or distractors, as compared with high-frequency words (e.g., Glanzer \& Bowles, 1976). Similarly, in the extralist cued-recall task, low-frequency words are more likely to be recalled (Nelson \& McEvoy, 2000; Nelson \& $\mathrm{Xu}, 1995)$. PIER 2 attributes these low-frequency advantages to differential priming effects. When studied, lowfrequency words are primed to higher levels than are 
high-frequency words because processing them produces a greater relative change in activation, as compared with baseline levels.

This interpretation attributes frequency effects to target accessibility, and not to target association. Target association explanations for frequency effects can be ruled out in several ways. First, forward strength and backward strength were carefully controlled at each level of word frequency, and yet low-frequency words showed greater priming effects. If the low-frequency advantage was due to target association, then such priming effects should have been eliminated, because target-to-cue strength was equivalent for low- and high-frequency targets. Second, normative studies of target frequency indicate that low- and high-frequency words have similar sized associative sets, equally strong associates, and equally well interconnected associates (Nelson \& McEvoy, 2000). However, the same normative studies indicate that low-frequency words are less likely to be produced as associates of other words in general and by their own associates in particular (lower resonance). Statistically speaking, low-frequency words are normally less accessible than high-frequency words because they appear less recently and in fewer contexts (Dennis \& Humphreys, 2001). In short, low-frequency words have lower baseline levels of accessibility, and when they are experienced, they tend to show relatively larger changes in activation that translate into larger priming effects. Because of these larger priming effects, low-frequency words are also more likely to be correctly recognized and rejected in recognition and correctly recalled in the extralist cuing task.

Implications for models of cued recall. Direct forward and backward links, shared associates, target frequency, connectivity, and set size have similar effects in priming and explicit cued-recall tasks (e.g., Nelson, Bennett, \& Leibert, 1997; Nelson et al., 1998). Words with stronger preexisting cue-to-target and target-to-cue connections or stronger shared associate links are more likely to be recovered under both explicit and implicit cuing conditions. Similarly, words that appear infrequently in the language, that have more connections among their associates, and that have relatively smaller sets of associates are more likely to be recovered regardless of the retrieval intention of the participant. Both priming and extralist cued-recall tasks appear to be affected in the same way by the same variables. This parallel is predicted by PIER 2, which attributes the effects of these variables to the priming of both the target and the connections involving its associates in LTWM (Nelson et al., 1998).

The parallel effects of these variables in these two tasks provide some support for the model and raise issues for other models. For example, the auto-associative model stores associations in the weights that connect sets of features (Chappell \& Humphreys, 1994). Episodic information is stored as context-to-list-item associations, semantic information as list-item-to-list-item associations, and perceptual information as intraitem associations. In extralist cued recall, the model computes the intersection between the test cue and its associates with the list items activated by the context cue. The output of the intersection process can be noisy, and a deblurring process that depends on nonsemantic features is used to clean it up. What is important here is that extralist cued recall is affected by all three sources of associations: context, semantic, and nonsemantic. In contrast, the model assumes that priming in free association depends on strengthening only the nonsemantic intraitem associations. Neither the context nor the semantic item-to-item associations within the list play a role (Humphreys et al., 2000). The findings reported in this article indicate that priming is not just a function of strengthening the target's nonsemantic features, and therefore the auto-associative model needs modification. Simply allowing semantic item-to-item associations to affect priming would allow the auto-associative model to explain many of the present findings, but note that such associations must involve the target and its item-to-item associates, not the item-to-item connections among the list words that are currently allowed in the extralist cued-recall version of the model. Such a change may move the auto-associative model toward PIER 2's assumptions about the implicit representation, which may not be acceptable to these theorists, but it would allow the auto-associative model to explain target set size as well as cue set size effects, target connectivity effects, and the effects of strengthening the preexisting target-to-associate links. It would also allow the auto-associative model to explain why a second study trial facilitates cued recall without affecting priming in the free-association task. A second study experience is likely to add much to the strength of a context-to-item connection (the explicit representation in PIER 2), but not much to an activation of a preexisting representation that has been processed by the memory system thousands of times in as many different contexts.

\section{REFERENCES}

Anderson, J. R. (1983). The architecture of cognition. Cambridge, MA: Harvard University Press.

BorING, E. G. (1957). A history of experimental psychology. New York: Appleton-Century-Crofts.

Chappell, M., \& Humphreys, M. S. (1994). An auto-associative neural network for sparse representations: Analysis and application to models of recognition and cued recall. Psychological Review, 101, 103-128.

Cramer, P. (1968). Word association. New York: Academic Press.

Dennis, S., \& Humphreys, M. S. (2001). A context noise model of episodic word recognition. Psychological Review, 108, 452-478.

Ebisinghaus, H. (1964). Memory: A contribution to experimental psychology. New York: Dover. (Original work published 1885)

Fox, P. W. (1968). Recall and misrecall as a function of cultural and individual word association habits and regulation of the recall environment. Journal of Verbal Learning \& Verbal Behavior, 7, 632-637.

Glanzer, M., \& Bowles, N. (1976). Analysis of the word frequency effect in recognition memory. Journal of Experimental Psychology: Human Learning \& Memory, 2, 21-31.

HintzMan, D. L. (1976). Repetition and memory. In G. H. Bower (Ed.), The psychology oflearning and motivation (Vol. 10, pp. 47-91). New York: Academic Press.

Horowitz, L. M., Brown, Z M., \& Weissbluth, S. (1964). Avail- 
ability and the direction of associations. Journal of Experimental Psychology, 68, 541-549.

Horowitz, L. M., \& PrytulaK, L. S. (1969). Redintegrative memory. Psychological Review, 76, 519-531.

Humphreys, M. S., Bain, J. D., \& Pike, R. (1989). Different ways to cue a coherent memory system: A theory for episodic, semantic, and procedural tasks. Psychological Review, 96, 208-233.

Humphreys, M. S., \& GAlbRaITH, R. C. (1975). Forward and backward associations in cued recall: Predictions from the encoding specificity principle. Journal of Experimental Psychology: Human Learning \& Memory, 1, 702-710.

Humphreys, M. S., Tehan, G., O'Shea, A., \& Bolland, S. W. (2000). Target similarity effects: Support for the parallel distributed processing assumptions. Memory \& Cognition, 28, 798-811.

JACOBY, L. L., \& HollingsheAd, A. (1990). Toward a generate/recognize model of performance on direct and indirect tests of memory. Journal of Memory \& Language, 29, 433-454.

KuČera, H., \& Francis, W. N. (1967). Computational analysis of present-day American English. Providence, RI: Brown University Press.

MAndler, G. (1980). Recognizing: The judgment of previous occurrence. Psychological Review, 87, 252-271.

Martin, J. G. (1964). Word-association frequency and the proximity effect. Journal of Verbal Learning \& Verbal Behavior, 3, 344-345.

Nelson, D. L., Bennett, D. J., Gee, N. R., Schreiber, T. A., \& McKINNEY, V. (1993). Implicit memory: Effects of network size and interconnectivity on cued recall. Journal of Experimental Psychology: Learning, Memory, \& Cognition, 19, 747-764.

Nelson, D. L., Bennett, D. J., \& Leibert, T. W. (1997). One step is not enough: Making better use of association norms to predict cued recall. Memory \& Cognition, 25, 785-796.

Nelson, D. L., BennetT, D. J., \& XU, J. (1997). Recollective and automatic uses of memory. Journal of Experimental Psychology: Learning, Memory, \& Cognition, 23, 872-885.

Nelson, D. L., \& McEvoy, C. L. (2000). What is this thing called frequency? Memory \& Cognition, 28, 509-522.

Nelson, D. L., McEvoy, C. L., \& Dennis, S. (2000). What is free association and what does it measure? Memory \& Cognition, 28, 887-899.

Nelson, D. L., McEvoy, C. L., \& Schreiber, T. A. (1999). The University of South Florida word association, rhyme and fragment norms. Available: http://www.usf.edu/FreeAssociation.

Nelson, D. L., McKinney, V. M., \& Bennett, D. J. (1999). Conscious and automatic uses of memory in cued recall and recognition. In B. H. Challis \& B. M. Velichkovsky (Eds.), Stratification in cognition and consciousness (pp. 173-202). Amsterdam: John Benjamins.

Nelson, D. L., McKinney, V. M., Gee, N. R., \& Janczura, G. A. (1998). Interpreting the influence of implicitly activated memories on recall and recognition. Psychological Review, 105, 299-324.

Nelson, D. L., Schreiber, T. A., \& Holley, P. E. (1992). The retrieval of controlled and automatic aspects of meaning on direct and indirect tests. Memory \& Cognition, 20, 671-684.

Nelson, D. L., \& XU, J. (1995). Effects of implicit memory on explicit recall: Set size and word frequency effects. Psychological Research, 57, 203-214.

Nelson, D. L., \& Zhang, N. (2000). The ties that bind what is known to the recall of what is new. Psychonomic Bulletin \& Review, 7, 604-617.

Nelson, D. L., Zhang, N., \& McKinney, V. M. (2001). The ties that bind what is known to the recognition of what is new. Journal of Experimental Psychology: Learning, Memory, \& Cognition, 27, 1147-1159.

Schreiber, T. A., \& Nelson, D. L. (1998). The relation between feelings of knowing and the number of neighboring concepts linked to the test cue. Memory \& Cognition, 26, 869-883.

Segal, S. J., \& Cofer, C. N. (1960). The effect of recency and recall on word association [Abstract]. American Psychologist, 15, 451.

SToRms, L. H. (1958). Apparent backward association: A situational effect. Journal of Experimental Psychology, 55, 390-395.

Tulving,E., \& Thomson, D. M. (1973). Encoding specificity and retrieval processes in episodic memory. Psychological Review, 80, 352-373.

Vaidya, C. J., Gabrieli, J. D. E., Keane, M. M., Monti, L. A., GutierreZ-Rivas, H., \& Zarella, M. M. (1997). Evidence for multiple mechanisms of conceptual priming on implicit memory tests. Journal of Experimental Psychology: Learning, Memory, \& Cognition, 23, 1324-1343.

Weldon, M. S., \& Coyote, K. C. (1996). Failure to find the pictorial superiority effect in implicit conceptual memory tests. Journal of Experimental Psychology: Learning, Memory, \& Cognition, 22, 670-686.

Zeelenberg, R., Shiffrin, R. M., \& RaAijmakers, J. G. (1999). Priming in a free association task as a function of association directionality. Memory \& Cognition, 27, 956-961.

\section{NOTES}

1. Following a long tradition, the direction of the strength manipulation will be defined relative to the cue or prime stimulus in this paper, so cue-to-target strength is forward strength and target-to-cue strength is backward strength. Of course, because free association is used to index preexisting strength, only forward strength is being measured in each direction.

2. When resonance and connectivity are ignored as separate effects, Equation 1 reduces to

$$
S\left(T_{i}\right)=\sum_{j=1}^{k} \sum_{i=1}^{n} A_{i j},
$$

where $A_{i j}=$ the activation strength in each cell of the matrix, $n=$ rows, and $k=$ columns. For individual target-to-associate links that have been primed, the formula is

$$
S\left(A_{j}\right)=\sum_{j=1}^{k} A_{j} .
$$

3. Equation 3 was not included because neither cue nor target set size was varied in these experiments. See Nelson et al. (1998) for this equation. 
APPENDIX A

Materials Used in Experiment 1

\begin{tabular}{|c|c|c|c|}
\hline \multicolumn{4}{|c|}{ Low-Frequency Lists 1 and 2} \\
\hline \multicolumn{2}{|r|}{ List 1} & \multicolumn{2}{|r|}{ List 2} \\
\hline Test Cues & High-Connectivity Targets & Test Cues & High-Connectivity Targets \\
\hline ATOM & PROTON & ASPHALT & PAVEMENT \\
\hline BACTERIA & FUNGUS & BRANCH & LEAF \\
\hline CLARINET & TRUMPET & BUMP & BRUISE \\
\hline DIVER & SCUBA & GEM & RUBY \\
\hline DWARF & MIDGET & GULP & SIP \\
\hline PENNY & NICKEL & HURRICANE & TORNADO \\
\hline ROBBERY & THEFT & MEDICATION & PRESCRIPTION \\
\hline TEAM & SOCCER & NAVIGATOR & AIRPLANE \\
\hline THREAD & SEW & OFFEND & INSULT \\
\hline TRIANGLE & GEOMETRY & SHOVEL & DIG \\
\hline WHISKEY & RUM & SLIPPERS & ROBE \\
\hline Test Cues & Low-Connectivity Targets & Test Cues & Low-Connectivity Targets \\
\hline ANTIDOTE & POISON & BARREL & PICKLES \\
\hline APPLIANCE & TOASTER & CLIFF & HANGER \\
\hline BEARD & SHAVE & DICTIONARY & THESAURUS \\
\hline CHARACTERISTIC & TRAIT & EGGS & SCRAMBLE \\
\hline CONTEST & WINNER & FASTEN & SEATBELT \\
\hline FIGHTER & BOXER & FINGER & TOE \\
\hline LODGE & SKI & MOTORCYCLE & HELMET \\
\hline MAZE & PUZZLE & PUFF & DRAGON \\
\hline OIL & GREASE & SLENDER & SKINNY \\
\hline PIGEON & DOVE & WALNUT & PECAN \\
\hline WASTED & GARBAGE & WISE & OWL \\
\hline
\end{tabular}

High-Frequency Lists 1 and 2

List 1

\begin{tabular}{lc}
\hline \multicolumn{1}{c}{ Test Cues } & High-Connectivity Targets \\
ALIKE & SIMILAR \\
BANG & GUN \\
BORROW & TAKE \\
BRAT & CHILD \\
DECIDE & THINK \\
DENTIST & DOCTOR \\
EDUCATION & COLLEGE \\
LOBBY & HALL \\
REGULAR & NORMAL \\
TELEVISION & RADIO \\
TREASURE & ISLAND \\
\multicolumn{1}{c}{ Test Cues } & \\
BENCH & LOW-CONNECtivity Targets \\
BLONDE & TABLE \\
BOMB & HAIR \\
CORE & NUCLEAR \\
EDITOR & CENTER \\
INITIAL & CHIEF \\
JUSTICE & FIRST \\
MORNING & PEACE \\
PEST & EARLY \\
SKATE & CONTROL \\
WISE & BOARD \\
\hline & OLD \\
\hline &
\end{tabular}

List 2

\begin{tabular}{lc}
\hline \multicolumn{1}{c}{ Test Cues } & High-Connectivity Targets \\
AEROBICS & ACTIVITY \\
ARTS & PERFORMANCE \\
BIBLE & RELIGION \\
BROOK & RIVER \\
HUGE & LARGE \\
JURY & TRIAL \\
MOOD & FEELING \\
NEVER & AGAIN \\
PURPLE & COLOR \\
VISION & SEE \\
WEATHER & TEMPERATURE \\
TeSt Cues & \\
BOUNDARY & LOW-CONnectivity Targets \\
CALCULATOR & LINE \\
CURIOSITY & NUMBERS \\
DONATION & INTEREST \\
ERROR & BLOOD \\
HIDE & WRONG \\
HOUR & FIND \\
HUNGRY & TIME \\
INDIVIDUAL & FULL \\
REAR & SINGLE \\
SLAVE & FRONT \\
& LABOR \\
\hline
\end{tabular}


APPENDIX B

Materials Used in Experiments 4 and 5

\begin{tabular}{|c|c|c|c|}
\hline \multicolumn{2}{|c|}{ List 1} & \multicolumn{2}{|c|}{ List 2} \\
\hline Test Cues & Targets & Test Cues & Targets \\
\hline \multicolumn{4}{|c|}{ High S-High M } \\
\hline INFANT & CHILD & PETALS & ROSE \\
\hline CIGAR & CIGARETTE & MEATBALLS & SAUCE \\
\hline SHUT & OPEN & SHOUT & SCREAM \\
\hline WAVES & SEA & HURRY & SLOW \\
\hline CHORUS & SONG & UTENSIL & SPOON \\
\hline DUSTPAN & SWEEP & PRONOUN & VERB \\
\hline \multicolumn{4}{|c|}{ High S-Low M } \\
\hline FAIRYTALE & BOOK & CONCLUSION & BEGINNING \\
\hline STEPS & CLIMB & NUN & CHURCH \\
\hline PINT & MILK & GLOBE & EARTH \\
\hline SKETCH & PICTURE & FLAME & HOT \\
\hline CO-PILOT & PLANE & DEBT & MONEY \\
\hline INFECTION & SICK & DEPUTY & POLICE \\
\hline \multicolumn{4}{|c|}{ Low S-High M } \\
\hline INCORRECT & CORRECT & DECADE & CENTURY \\
\hline BAIT & HOOK & BANQUET & FEAST \\
\hline TIMBER & LUMBER & TRIGONOMETRY & GEOMETRY \\
\hline EVENING & MORNING & SPRING & SEASON \\
\hline SNOOZE & SNORE & SEAM & STITCH \\
\hline CLEVER & WISE & CALORIES & WEIGHT \\
\hline \multicolumn{4}{|c|}{ Low S-Low M } \\
\hline INSECT & BEE & BUBBLE & BATH \\
\hline SAME & EXACT & DESTINY & DREAM \\
\hline NAIL & FINGER & TEARS & EYE \\
\hline MAZE & PUZZLE & МOB & GANG \\
\hline BUCKLE & SHOE & RUBBER & TIRE \\
\hline ARROW & STRAIGHT & CONCEPT & UNDERSTAND \\
\hline
\end{tabular}

Note-S, shared associate strength; M, mediated associate strength. 


\section{APPENDIX C \\ Illustration of How Net Cue-Target Priming is Computed in PIER 2}

1. $N \times n$ associative matrix for the target RUM and Equation 1 for calculating resonance and connectivity ( 1 a in Nelson \& Zhang, 2000). The activation of RUM is assigned a nominal value of 1.0 because it is presented, but it can be assigned a value related to its printed frequency. Reading along the rows, all pairwise links are taken from free association norms (e.g., RUM-to-COKE $=.28$, wHISKEY-to-rum $=.08$, and so on). The model assumes that such norms provide a baseline index of the likely activation strength of each pairwise connection in its associative network when RUM is experienced. Immediately after encoding, rum's primed self-strength and its primed connections to each of its associates is given in the bottom row. The comparison of the activations shown in the first and last rows shows how encoding RUM primes its self-strength as well as its connections to its associates (e.g., its self-strength increases from 1.00 to 1.16, and its connection to drink increases from .16 to 1.23). Equation 1 indicates that the net activation strength of RUM is determined by adding its primed self-strength to the primed links for each of its associates. Preexisting connections to the target from its associates, shown in the first column (resonance), add to connections among the associates themselves, shown in the remaining columns (connectivity), to increase the target's activation level. In general, the greater the number and strength of such connections, the higher the activation level of the target. Note: S, strength; T, target; A, associate:

$$
\begin{aligned}
S\left(T_{i}\right) & =\left[S(T, T)+\sum_{i=1}^{n} S\left(A_{i}, T\right)\right]+\sum_{j=1}^{n}\left[S\left(T, A_{j}\right)+\sum_{i=1}^{n} S\left(A_{i}, A_{j}\right)\right] \\
& =1.00+.16+.34+1.23+.48+.20+.80+.16+.80+.68+.23=6.08 .
\end{aligned}
$$

\begin{tabular}{|c|c|c|c|c|c|c|c|c|c|c|}
\hline & Rum & Coke & Drink & Liquor & Vodka & Alcohol & Whiskey & Beer & Drunk & Booze \\
\hline Rum & 1.00 & .28 & .16 & .16 & .10 & .10 & .04 & .03 & .03 & .02 \\
\hline Coke & & & .22 & & & & & & & \\
\hline Drink & & .06 & & .03 & .02 & .05 & .10 & .06 & & \\
\hline Liquor & .04 & & .07 & & .05 & .11 & & .13 & .12 & .05 \\
\hline Vodka & .03 & & .19 & .07 & & .12 & .01 & .01 & .12 & \\
\hline Alcohol & & & .15 & & .01 & & & .24 & .11 & \\
\hline Whiskey & .08 & & .08 & .08 & & .05 & & .05 & .12 & .14 \\
\hline Beer & & & .18 & & .01 & .03 & & & .06 & \\
\hline Drunk & .01 & & .06 & .03 & & .13 & & .10 & & .02 \\
\hline Booze & & & .12 & .11 & .01 & .21 & .01 & .18 & .12 & \\
\hline Sum & 1.16 & .34 & 1.23 & .48 & .20 & .80 & .16 & .80 & .68 & .23 \\
\hline
\end{tabular}

2. Calculation of Equation 2 with WHISKEY as the test cue and RUM as the target. The priming results of Equation 1 for the target, for the target-to-testcue-link, and for each shared associate are included in the top row of the retrieval matrix. This equation assumes that prior study of the target primes its self-strength and the strengths of the links between it and each of its associates (shown in bold print). Intersecting links from the test cue are unaffected by the target presentation. The cue-to-target links and cue-to-shared associate links (S), shown in the bottom row, are left at baseline levels estimated by free-associationnorms (e.g., the forward strength from WHISKEYto-RUM is still .08). Mediated links are not included in the calculation for priming, as they are in the calculation for cued recall, because such mediators had no effect on priming here. With these assumptions, Equation 2 is cal-

\begin{tabular}{|c|c|c|c|c|c|c|c|c|}
\hline Intersection & $\begin{array}{l}\text { Target: } \\
\text { Rum }\end{array}$ & $\begin{array}{c}\text { Cue: } \\
\text { Whiskey }\end{array}$ & $\begin{array}{c}\text { S: } \\
\text { Drink }\end{array}$ & $\begin{array}{c}\text { S: } \\
\text { Liquor }\end{array}$ & $\begin{array}{c}\text { S: } \\
\text { Alcohol }\end{array}$ & $\begin{array}{c}\text { S: } \\
\text { Beer }\end{array}$ & $\begin{array}{c}\text { S: } \\
\text { Drunk }\end{array}$ & $\begin{array}{c}\text { S: } \\
\text { Booze }\end{array}$ \\
\hline Rum & 6.08 & .16 & 1.23 & .48 & .80 & .80 & .68 & .23 \\
\hline Whiskey & .08 & 1.00 & .08 & .08 & .05 & .05 & .12 & .14 \\
\hline
\end{tabular}
culated as

(Manuscript received February 12, 2001; revision accepted for publication December 11, 2001.) 